\title{
A Study on the Association of Perceived Spiritual Beliefs, Practices, and Well-being of Breast Cancer Patients in a Tertiary General Hospital
}

\author{
Kimberly S. Cariñgal, MD, Manuel F. Medina, Jr., MD and Martha Jane Pauline S. Umali, MD
}

Section of Supportive, Hospice, and Palliative Medicine, Department of Family and Community Medicine,

Philippine General Hospital, University of the Philippines Manila

\begin{abstract}
Background. Among Filipino females, breast cancer is the leading malignancy which warrants palliative care that includes spiritual care to help improve quality of life and well-being.

Objective. Determine the associations of perceived spiritual beliefs and spiritual practices with perceived spiritual well-being among breast cancer patients consulting at the University of the Philippines - Philippine General Hospital (UP-PGH).
\end{abstract}

Methods. This was an analytical cross-sectional study using non-probability convenience sampling of adult females with breast cancer at the UP-PGH Breast Cancer Clinic (BCC). The survey utilized a self-administered questionnaire with sections on general demographics, spiritual beliefs, spiritual practices, and spiritual well-being. Descriptive statistics were used and analysis of associations was done through Fisher's exact test at a $5 \%$ level of significance.

Results. Among 219 study participants, almost all reported having perceptions of strong spiritual beliefs, adequate spiritual practices, and good spiritual well-being. Associations were found between perceived spiritual beliefs and spiritual well-being $(F=51.2, p<0.001 ; R=0.4, p<0.001)$ and between perceived spiritual practices and spiritual well-being $(F=62.0, p<0.001 ; R=0.4, p<0.001)$.

Conclusion. The associations found of perceived spiritual beliefs and spiritual practices with perceived spiritual well-being should be considered in providing spiritual care as part of the comprehensive management and palliative care for Filipino breast cancer patients.

Key Words: spirituality, well-being, cancer

Paper presented at the Section of Supportive, Hospice, and Palliative Medicine, Department of Family and Community Medicine, on December 11, 2018 at the University of the Philippines - Philippine General Hospital, Taft Avenue, Ermita, Manila, Philippines.

Corresponding author: Kimberly S. Cariñgal, M.D.

Section of Supportive, Hospice, and Palliative Medicine,

Department of Family and Community Medicine

Philippine General Hospital

University of the Philippines Manila

Taft Avenue, Manila 1000, Philippines

Email: ksc_605@yahoo.com

\section{INTRODUCTION}

Importance of Spirituality in Palliative Care

Spirituality is an important aspect of palliative care. During illness, it has been observed that people not only utilize the medical aspect of management but also turn to spirituality as part of care and coping. Studies indicate that among patients, $94 \%$ believe that spiritual health is as important as physical health, $40 \%$ use faith to cope with illness, and $25 \%$ use prayer for healing. ${ }^{1}$ Palliative care patients with higher levels of spirituality have better quality of life and that supporting spiritual well-being is useful, especially as patients approach the end of life. ${ }^{2} \mathrm{~A}$ number of studies recognize the importance of addressing the spiritual pain of patients as part of total health care. ${ }^{3}$ 
In the Philippines, a study reported that spirituality and religiosity among Filipinos are strongly associated. ${ }^{4} \mathrm{~W}$ ith the country ranked $10^{\text {th }}$ in the world in religiosity, nearly $87 \%$ of Filipinos consider religion important in life. ${ }^{5}$ Filipinos are also considered to have a deep sense of spirituality. ${ }^{6}$ Spirituality and religion are ingrained in the culture of Filipinos and day-to-day practices which include how to cope with illness.

\section{Spiritual Beliefs and Practices}

Spiritual beliefs and practices are defined as beliefs and outward practices that relate to or affirm the experience of one's existence. ${ }^{7}$ Spiritual beliefs and practices are essential in influencing healthcare decision-making and healthcare outcomes, including coping, quality of life, and pain management. ${ }^{2}$ Spiritual beliefs which help patients are beliefs of being in the loving presence of a God or a higher power, that death is not the end, and of living on through children or descendants. ${ }^{8}$ Spiritual practices which help patients include praying - whether through individual prayers or through attendance of structured religious devotions, rituals, or processions - or external manifestations of piety by the use of candles, incense, statues, medals, rosaries, and others. ${ }^{9}$

Such beliefs and practices give people a sense of comfort and direction in their condition in addition to their coping. A study on religious beliefs towards the end of life among the elderly showed that many considered themselves religious and/or supported by religion; most believed in a God or higher power and many patients believed in the afterlife. ${ }^{10}$ The few studies that have looked into spiritual practices and the relationship with quality of life in patients with advanced illness showed mixed results in terms of improvements in psychological and spiritual quality of life for patients. ${ }^{2}$ Any spiritual practice may or may not be helpful at times, but what affects health outcome is how people make use of them to cope with their situation. ${ }^{11}$

Filipinos utilize spirituality and religiosity in coping with issues and problems. ${ }^{5}$ The help-seeking behavior related to health and coping with diseases and end-of-life care of others have been influenced by spirituality and religious beliefs and practices. ${ }^{5,12-14}$ For example, some have religious devotions to invoke God or a higher power to grant the need of the devotee (for example, healing). ${ }^{5}$ When Filipinos are left with no other recourse or can no longer do anything about a dire situation - as in the case of terminal illness - care is turned over in the hands of God ("Ipagpasa-Diyos na natin").

\section{Spiritual Well-Being}

There is limited literature looking into spiritual wellbeing from the Filipino perspective. According to a local study, Filipinos considered presence of personal spiritual well-being when there is a feeling of having a satisfying relationship with God, when there is satisfaction in life with meaning and purpose, and view prayer as important and satisfying as it is considered a direct link to God. ${ }^{9}$ Among older Filipino adults, spiritual well-being was found to be inversely correlated with fear of death. ${ }^{9}$

From the perspective of palliative care patients, spiritual well-being is important. ${ }^{15}$ Spiritual well-being gives patients hope not just limited in this life but also for hope after death for the patients and the people who will be left behind.

\section{Association of Spiritual Beliefs and Practices with the Physical, Mental, Social, and Psychological Well-Being Among Cancer Patients}

Studies showed that spiritual beliefs provided comfort to cancer patients and that its different dimensions were associated with the different aspects of health. ${ }^{16}$ Patients who felt the emotional dimension of spirituality reported both better physical and mental health with patients having greater ability to perform daily activities and reported fewer symptoms regardless of their spiritual or religious practices such as going to church or praying. ${ }^{16}$ On the other hand, patients with stronger spiritual beliefs, spiritual wellbeing, and religious coping also reported better social and psychological health. ${ }^{17}$

\section{Spirituality Among Breast Cancer Patients}

More people are being diagnosed with chronic or terminal illnesses with cancer patients ranking second globally of those requiring end-of-life palliative care. ${ }^{18}$ Philippine data show that cancer is also among the top three causes of morbidity and mortality with breast cancer as the leading cause of cancer among females and is among the top three causes of new cancer deaths for both sex. ${ }^{19}$

Because of the importance of spirituality among cancer patients, a study was done on Filipino-Americans with breast cancer which showed that patients used spirituality and religion to help them cope with the condition. ${ }^{14} \mathrm{~A}$ similar study in this institution would give insight into the condition in the local setting, particularly regarding the spiritual beliefs, spiritual practices, and spiritual well-being among breast cancer patients.

This study aimed to determine the associations of perceived spiritual beliefs and spiritual practices with the perceived spiritual well-being of breast cancer patients consulting at the University of the Philippines - Philippine General Hospital (UP-PGH). Specifically, this study aimed to: (1) describe the perceived spiritual beliefs, spiritual practices, and spiritual well-being of breast cancer patients; and (2) to determine the associations of the perceived spiritual beliefs and spiritual practices with the perceived spiritual well-being among breast cancer patients.

\section{METHODS}

\section{Study Design}

Ethics review and approval for the study were obtained from the University of the Philippines - Manila Research Ethics Board (UPMREB) PGH Review Panel. 
The study design was an analytical cross-sectional study using non-probability convenience sampling. Descriptive statistics were used to present and analyze the nominal and ordinal variables.

\section{Study Setting and Participants}

The population was adult female breast cancer patients aged 19 years old and above consulting at the UP-PGH Breast Cancer Clinic (BCC) in the Cancer Institute (CI). Those who were medically stable and coherent; able to communicate verbally or through writing; able to understand and communicate in Filipino or English; and who gave informed consent were included in the study. The sample size computed for this study was 211 participants. The study was conducted from August to October 2018.

\section{Data Collection}

An original self-administered survey questionnaire was formulated by the investigators after reviewing different studies and questionnaires. ${ }^{21-25}$ The bases for the survey questionnaire are the constructs of the concepts of spiritual beliefs, spiritual practices, and spiritual well-being. The survey utilized a questionnaire with four sections inquiring the (1) general demographics, (2) perception of spiritual beliefs, (3) perception of spiritual practices, and (4) perception of the spiritual well-being of the participants.

1. General demographics section. The general demographics section is a survey on the demographic details of the participants including the age, place of residence, civil status, religion, educational attainment, occupation, stage of breast cancer, and functionality of the participants.

2. Spiritual beliefs section. The spiritual beliefs section is a survey regarding the perception of spiritual beliefs and the perception of the strength of spiritual beliefs in the life of the participants.

3. Spiritual practices section. The spiritual practices section is a survey regarding the perception of spiritual practices, in what form, with whom, and frequency these are practiced, and the perception of the adequacy of spiritual practices in the life of the participants.

4. Spiritual well-being section. The spiritual well-being section is a survey regarding the perception of spiritual well-being based on the constructs of spiritual wellbeing and the perception of how good spiritual wellbeing is in the life of the participants.

After the pilot survey, the actual study survey was conducted at the UP-PGH BCC by the principal investigator using the self-administered survey questionnaires on the participants after obtaining informed consent.

\section{Study Outcomes}

The study outcomes include a description of the demographics and perceptions of spiritual beliefs, spiritual practices, and spiritual well-being of the participants, as well as the associations of perceived spiritual beliefs with spiritual well-being and of perceived spiritual practices with spiritual well-being.

The outcomes for spiritual beliefs report the percent of participants who: a) consider being spiritual or non-spiritual persons; b) believe that there is a God or a higher power; c) think there is meaning in life in relation to spirituality; d) think that religion helps during misfortune, particularly in illness; e) have spiritual beliefs in relation to faith and hope in healing; f) have spiritual beliefs regarding death and dying; g) "strongly agree," "agree," "disagree," or "strongly disagree" that spiritual beliefs are strong; and h) rate from 0 to 10 the strength of spiritual beliefs in life.

The spiritual practices outcomes describe the percent of participants': a) spiritual practices (i.e., prayer, reading holy scriptures, chanting/singing spiritual/religious verses/songs, listening to spiritual/religious music, attending spiritual/ religious services, using external manifestations of piety like candles, incense, processions, statues, medals, rosaries, and others); b) frequency of doing spiritual practices; c) practice of spirituality whether individually, with family, with nonfamily members, or mixed; d) agreement whether "strongly agree," "agree," "disagree," or "strongly disagree" that spiritual practices are adequate in coping with illness; and e) rating from 0 to 10 of the adequacy of spiritual practices in life.

The description of the perception of spiritual wellbeing of participants reports the percent of participants who: a) have a satisfying relationship with a God or a higher power; b) have an important and satisfying direct link to God; c) feel at peace; d) feel a sense of purpose in life; e) feel satisfaction in life with meaning and purpose; f) find comfort and strength in faith and spiritual beliefs; g) perceive illness as strengthening faith or spiritual beliefs; $h$ ) are able to do spiritual practices during illness; i) "strongly disagree," "disagree," "agree," or "strongly agree" that spiritual well-being is very good; and $\mathrm{j}$ ) rate from 0 to 10 overall spiritual well-being.

\section{Data Analysis}

Chi-square analysis at a 5\% level of significance was initially planned to be utilized in determining the associations of the perceived spiritual beliefs with the perceived spiritual well-being and of the perceived spiritual practices with the perceived spiritual well-being on a Likert scale ("strongly disagree," "disagree," "agree," or "strongly agree”). However, the outcomes for the associations of the perceived spiritual beliefs with the perceived spiritual well-being and of the perceived spiritual practices with the perceived spiritual well-being were eventually computed by Fisher's exact test due to the minimal counts for cells under "strongly disagree" and "disagree." 


\section{RESULTS}

\section{Baseline Characteristics of Participants}

A total of 221 participants initially consented to be part of the study. However, two of the participants had incomplete data resulting in a total of 219 participants included in the study (Table 1 ). The mean age was 51.4 years ( $\mathrm{SD} \pm 10.6)$. Many were married (63.0\%), Roman Catholic (75.8\%), unemployed (71.2\%), at least high school graduates (76.2\%), and living outside Metro Manila (57.1\%). The majority were diagnosed with stage 3 or 4 breast cancer $(57.5 \%)$ and had a performance status of Eastern Cooperative Oncology Group (ECOG) 0 or 1 (85.9\%).

\section{Spiritual Beliefs}

Spiritual beliefs pertained to non-sectarian spiritual beliefs regardless of religion or perception of the degree of religiosity. Most of the participants indicated having a perception of strong spiritual beliefs. All believed there is a God or a higher power. Almost all considered themselves spiritual persons (97.3\%), think there is meaning in life in relation to spirituality (99.5\%), think that religion helps during misfortune, particularly in illness (98.2\%), have spiritual beliefs in relation to faith and hope in healing (99.1\%), and have spiritual beliefs regarding death and dying (90.0\%). The majority (98.7\%) "agreed" and "strongly agreed" that their spiritual beliefs were strong with an overall mean self-rating of 9.0/10 $(\mathrm{SD} \pm 1.6)$.

\section{Spiritual Practices}

All participants engaged in some form of spiritual practice (Table 2). All prayed, varying only in the frequency (always praying, 85.4\%). Most also practiced some other spiritual practices (for example, reading religious material, singing religious songs, listening to religious music, attending spiritual/religious services, using religious objects) but also varied in the frequency of performing them with many only performing these other spiritual practices sometimes (35.253.0\%). Companionship during spiritual practices was with family $(41.6 \%)$, mixed with either family or non-relatives $(28.3 \%)$ or with non-relatives only $(7.3 \%)$ while a number preferred to perform spiritual practices alone $(22.8 \%)$. The majority (92.3\%) "agreed" and "strongly agreed" that their spiritual practices were adequate with an overall mean self-rating of 8.2/10 $(\mathrm{SD} \pm 1.9)$.

\section{Spiritual Well-Being}

Most of the participants indicated having a perception of good spiritual well-being. Almost all considered themselves as having a satisfying relationship with a God or a higher power (98.2\%), having an important and satisfying direct link to God (99.1\%), feeling at peace (99.1\%), feeling a sense of purpose in life (96.8\%), feeling satisfaction in life with meaning and purpose (97.7\%), finding comfort and strength in faith and spiritual beliefs (99.1\%), perceiving
Table 1. Demographic profile of participants $(\mathrm{N}=219)$

\begin{tabular}{|c|c|}
\hline Variables & n (\%) \\
\hline Age in years $(X \pm S D)$ & 51.4 years $(S D \pm 10.6)$ \\
\hline $\begin{array}{l}\text { Age Group } \\
20-29 \text { years } \\
30-39 \text { years } \\
40-49 \text { years } \\
50-59 \text { years } \\
60-69 \text { years } \\
70-79 \text { years } \\
>79 \text { years }\end{array}$ & $\begin{array}{c}4(1.8 \%) \\
29(13.2 \%) \\
62(28.3 \%) \\
71(32.4 \%) \\
44(20.1 \%) \\
9(4.1 \%) \\
0(0)\end{array}$ \\
\hline $\begin{array}{l}\text { Place Where Participant Lives } \\
\text { Metro Manila } \\
\text { Outside Metro Manila }\end{array}$ & $\begin{array}{c}94(42.9 \%) \\
125(57.1 \%)\end{array}$ \\
\hline $\begin{array}{l}\text { Civil Status } \\
\text { Single } \\
\text { Married } \\
\text { Separated } \\
\text { Widow } \\
\text { With live-in partner }\end{array}$ & $\begin{array}{c}41(18.7 \%) \\
138(63.0 \%) \\
9(4.1 \%) \\
21(9.6 \%) \\
10(4.6 \%)\end{array}$ \\
\hline $\begin{array}{l}\text { Religion } \\
\text { Roman Catholic } \\
\text { Born Again Christian } \\
\text { Iglesia ni Cristo } \\
\text { Protestant } \\
\text { Muslim } \\
\text { Baptist } \\
\text { Church of God International } \\
\text { Iglesia ng Diyos kay Kristo, } \\
\text { Hesus Haligi at Suhay ng } \\
\text { Katotohanan (Church of God) } \\
\text { Jehovah's Witness } \\
\text { Mormon } \\
\text { The Church of Jesus Christ of Latter } \\
\text { Day Saints } \\
\text { No religion }\end{array}$ & $\begin{array}{c}166(75.8 \%) \\
27(12.3 \%) \\
11(5.0 \%) \\
6(2.7 \%) \\
2(0.9 \%) \\
1(0.5 \%) \\
1(0.5 \%) \\
1(0.5 \%)\end{array}$ \\
\hline $\begin{array}{l}\text { Educational Attainment } \\
\text { No formal education } \\
\text { Elementary undergraduate } \\
\text { Elementary graduate } \\
\text { High school undergraduate } \\
\text { High school graduate } \\
\text { College undergraduate } \\
\text { College graduate } \\
\text { Vocational } \\
\text { Post graduate } \\
\end{array}$ & $\begin{array}{c}2 \text { (0.9\%) } \\
11(5.0 \%) \\
18(8.2 \%) \\
9(4.1 \%) \\
86(39.3 \%) \\
18(8.2 \%) \\
59(26.9 \%) \\
12(5.5 \%) \\
4(1.8 \%)\end{array}$ \\
\hline $\begin{array}{l}\text { Occupation } \\
\text { Unemployed } \\
\text { Self-employed } \\
\text { Employee (private) } \\
\text { Employee (government) } \\
\text { Others (e.g., odd jobs, retiree) }\end{array}$ & $\begin{array}{c}152(71.2 \%) \\
11(5.0 \%) \\
19(8.7 \%) \\
13(5.9 \%) \\
20(9.1 \%)\end{array}$ \\
\hline $\begin{array}{l}\text { Stage of Breast Cancer } \\
1 \\
2 \\
3 \\
4\end{array}$ & $\begin{array}{c}7(3.2 \%) \\
86(39.3 \%) \\
104(47.5 \%) \\
22(10.0 \%)\end{array}$ \\
\hline Number of Months Diagnosed $(X \pm S D)$ & $25.5(\mathrm{SD} \pm 34.9)$ \\
\hline $\begin{array}{l}\text { ECOG Performance Scale } \\
0 \\
1 \\
2 \\
3 \\
4\end{array}$ & $\begin{array}{c}74(33.8 \%) \\
114(52.1 \%) \\
29(13.2 \%) \\
2(0.9 \%) \\
-\end{array}$ \\
\hline
\end{tabular}


Table 2. Perceived spiritual practices of participants ( $N=219)$

\begin{tabular}{|c|c|c|c|c|c|}
\hline & \multirow[b]{2}{*}{ Spiritual Practices } & \multicolumn{4}{|c|}{$\mathrm{n}(\%)$} \\
\hline & & $\begin{array}{l}\text { Always } \\
\text { (Daily) }\end{array}$ & $\begin{array}{c}\text { Often } \\
\text { (Weekly) }\end{array}$ & $\begin{array}{c}\text { Sometimes } \\
\text { (Monthly or less) }\end{array}$ & Never \\
\hline (a) & Prayer & $187(85.4)$ & $21(9.6)$ & $11(5.0)$ & $0(0)$ \\
\hline (b) & Reading holy scriptures & $52(23.7)$ & $34(15.5)$ & $102(46.6)$ & $31(14.2)$ \\
\hline (c) & Chanting/Singing religious verses/songs & $51(23.3)$ & $41(18.7)$ & $112(51.1)$ & $15(6.8)$ \\
\hline (d) & Listening to religious music & $50(22.8)$ & $48(21.9)$ & $103(47.0)$ & $18(8.2)$ \\
\hline (e) & Attending spiritual/religious services & $39(17.8)$ & $56(25.6)$ & $116(53.0)$ & $8(3.7)$ \\
\hline (f) & $\begin{array}{l}\text { Using external manifestations of piety like candles, incense, } \\
\text { processions, statues, medals, rosaries, and others }\end{array}$ & $60(27.4)$ & $18(8.2)$ & $77(35.2)$ & $64(29.2)$ \\
\hline
\end{tabular}

Table 3. Association and correlation coefficient for the association of perceived spiritual beliefs, spiritual practices, and spiritual well-being

\begin{tabular}{lcccc} 
& \multicolumn{4}{c}{ Spiritual Well-being } \\
\cline { 2 - 5 } \multicolumn{1}{c}{ Parameter } & $\begin{array}{c}\text { Fisher's exact } \\
\text { test (F) for } \\
\text { association }\end{array}$ & $\mathbf{p}$-value (p) & $\begin{array}{c}\text { Correlation } \\
\text { coefficient for } \\
\text { association (R) }\end{array}$ & p-value (p) \\
Spiritual Beliefs & 51.2 & $<0.001$ & 0.4 & $<0.001$ \\
Spiritual Practices & 62.0 & $<0.001$ & 0.4 & $<0.001$ \\
\hline
\end{tabular}

illness as strengthening faith or spiritual beliefs (96.8\%), and being able to do spiritual practices during illness (95.4\%). The majority (98.6\%) "agreed" and "strongly agreed" that their spiritual well-being was very good with an overall mean self-rating of 9.0/10 $(\mathrm{SD} \pm 1.7)$.

\section{Association of Spiritual Beliefs, Spiritual Practices, and Spiritual Well-Being}

The results showed clumping of answers towards "agreed" and "strongly agreed" and minimal counts for "disagree" and "strongly disagree." Results showed a statistically significant association between perceived spiritual beliefs and perceived spiritual well-being (Fisher's exact test, $F=51.2, \mathrm{p}<0.001$ ) with a direct relationship (correlation coefficient, $\mathrm{R}=0.4$, $\mathrm{p}<0.001$ ) (Table 3). Results also showed a statistically significant association between perceived spiritual practices and perceived spiritual well-being $(F=62.0, p<0.001)$ with a direct relationship $(\mathrm{R}=0.4, \mathrm{p}<0.001)$.

\section{DISCUSSION}

The results from the participants showed that there was an association of perceived spiritual beliefs with perceived spiritual well-being as well as an association of perceived spiritual practices with perceived spiritual well-being. However, the results were applicable only for those who agreed and strongly agreed on the perception of having strong spiritual beliefs, adequate spiritual practices, and good spiritual well-being. Since the number of participants who disagreed or strongly disagreed with these perceptions was very small, this precluded the analysis of those who disagreed or strongly disagreed.

The association of perception of strong spiritual beliefs with good spiritual well-being among the participants may be due to the feeling of connectedness to something outside of the self. ${ }^{14}$ All participants believed that there is a God or a higher power to which they turned to during illness which may be attributed to the increased use of spiritual resources in dealing with serious illnesses like cancer. ${ }^{26}$ Almost all participants also stated putting faith and hope first in God for healing followed by their beliefs in medical interventions which was a similar belief in a previous study. ${ }^{27}$ Almost all participants have beliefs regarding death and dying related to the religion they practiced which give comfort by offering a relative certainty of what to expect after death as well as perceptions of having strong spiritual beliefs which contribute to a positive outlook in life..$^{28-29}$

On the other hand, the association of perception of adequate spiritual practices with good spiritual well-being may be ascribed to cultural and societal influences and social support of spiritual practices on people. ${ }^{14}$ All participants performed some kind of spiritual practice, particularly prayer, regardless of religion which gave comfort, hope, and a more positive sense of well-being. ${ }^{14,30}$ Participants practiced prayer even though they had good functionality in contrast to a previous study which found a greater practice of prayer among those with poorer functionality. ${ }^{31}$ Some participants noted that although they were limited by their physical weakness, the continued practice of prayer could be due to the ease with which prayer can be done as well as to the ingrained practice of praying in Filipino culture and society. ${ }^{32}$ Progression of disease severity and decrease in functional capacity may eventually lead to further limitation of spiritual practices. It was also notable that most participants observed spiritual practices with family or with members of their religious groups instead of practicing alone which a previous study found affords comfort to patients through a sense of social support. $^{32}$ These can be further corroborated by findings 
in a previous study which found that spiritual practice can enhance spiritual well-being. ${ }^{33}$

In spite of having breast cancer, many of the participants considered themselves to have good spiritual well-being. Studies have found that those who reported having good spiritual well-being were better able to cope with their illnesses. ${ }^{30}$ Although some of the participants were initially saddened and questioned why they were afflicted with the disease, most of the participants said having the disease strengthened their spirituality and faith instead of weakening them. Among the factors that contribute to positive psychospiritual well-being are prognostic awareness, family and social support, autonomy, and hope and meaning of life with these patients better able to cope with the terminal illness and find meaning during the experience. ${ }^{34} \mathrm{~A}$ previous study found that functional capacity had a strong effect on well-being. ${ }^{35}$ As many of the participants in the study were highly functional with a performance status of ECOG 0 or 1 , this may account for why many of the study participants had a perception of good spiritual well-being.

A limitation of this study is that it only provided a snapshot of the perceived spiritual beliefs, spiritual practices, and spiritual well-being of patients at a particular point in time of the disease. Investigating the possible changes of perceived spiritual beliefs, spiritual practices, and spiritual well-being as the stage of the disease progresses may also provide insight on how increasing disease severity and declining functional capacity may affect the perceived spiritual beliefs, spiritual practices, and spiritual well-being of patients during illness.

Another limitation is the low number of nonChristian participants in this study. Further studies may be done specifically to explore the perceived spiritual beliefs, spiritual practices, and spiritual well-being among nonChristian patients. The use of mixed methods of quantitative and qualitative studies may also further provide detailed descriptions of the perceived spiritual beliefs, spiritual practices, and spiritual well-being among patients.

Further studies may also explore the possible association of demographic, clinical, or psychosocial factors on the perceived spiritual beliefs, spiritual practices, and spiritual well-being of breast cancer patients. Investigating the possible association of these factors with different spiritual parameters may help in determining patients who may be at greater risk of poor spiritual well-being and who may consequently need in-depth spiritual interventions and referral to spiritual care specialists.

\section{CONCLUSION AND RECOMMENDATION}

Participants in this study perceived having strong spiritual beliefs (in God or a higher power, being spiritual, the meaning of life, religion helping in illness, faith, and hope for healing, and death and dying), adequate spiritual practices (praying and other external manifestations of piety), and good spiritual well-being (satisfaction with relationship and direct link with God or a higher power, feeling at peace, having purpose, satisfaction and meaning in life, finding comfort and strength in faith and beliefs, perceiving illness as strengthening faith or beliefs, and being able to observe spiritual practices even during illness). This study showed an association with a direct relationship between perceived spiritual beliefs and perceived spiritual well-being $(\mathrm{F}=51.2, \mathrm{p}<0.001 ; \mathrm{R}=0.4, \mathrm{p}<0.001)$ and an association with a direct relationship between perceived spiritual practices and perceived spiritual well-being $(\mathrm{F}=62.0, \quad \mathrm{p}<0.001$; $\mathrm{R}=0.4, \mathrm{p}<0.001$ ).

It is important to recognize that spirituality in terms of beliefs and practices influence spiritual well-being and, consequently, the needed spiritual care as part of the comprehensive management and palliative care for Filipino breast cancer patients. Furthermore, considering the spiritual beliefs and practices may contribute to improving overall well-being, healthcare outcomes, and quality of life of breast cancer patients and their families.

\section{Statement of Authorship}

The author conceptualized the study, collected, encoded, collated, and analysed the data for the study, and wrote the initial and final research paper.

Co-authors supervised and collaborated with the author in developing the study, the analysis of the findings, and the revisions on the final research paper and approved the final version submitted.

\section{Author Disclosure}

All authors declared no conflicts of interest in this study.

\section{Funding Source}

This study was funded by the author.

\section{REFERENCES}

1. Saguil A, Phelps K. The spiritual assessment. American Family Physician. 2012 Sep 15;86(6):546-50. [cited 2017 Nov 30]. Available from: https://www.aafp.org/afp/2012/0915/p546.html.

2. Puchalski CM, Ferrell B, Otis-Green S, Handzo G. Overview of spirituality in palliative care [Online]. c2018-2019 [cited 2018 Mar 15]. Available from: https://www.uptodate.com/contents/overview-ofspirituality-in-palliative- care\#H14620274.

3. Mission Hospice \& Home Care, Understanding spiritual care as part of hospice [Online]. c2017-2019 [cited 2017 Nov 17]. Available from: https://www.missionhospice.org/spirituality/understanding-spiritualcare-part-hospice/.

4. Batara JBL. Overlap of religiosity and spirituality among Filipinos and its implications towards religious prosociality. International Journal of Research Studies in Psychology. 2015 Jul;4(3):3-21. [cited 2018 Apr 20]. Available from: https://www.researchgate. net/publication/276519588_Overlap_of_religiosity_and_spiritu ality_among_Filipinos_and_its_implications_towards_religious_ prosociality. DOI: 10.5861/ijrsp.2015.1090.

5. Bagaoisan, AJ. Why Filipinos are among world's most religious [Online]. 2016 Jan 8 [cited 2018 Apr 20]. Available from: http://news. abs-cbn.com/focus/01/07/16/why- filipinos-are-among-worlds-mostreligious. 
6. Yabut HJ. The development of the Filipino Spirituality Scale [Dissertation]. Manila: De La Salle University; 2017. Summary; p. 1. Available from: https://www.dlsu.edu.ph/conferences/arts_congress/ 2017/_pdf/paper-45.pdf.

7. Merriam-Webster [Online]. 2019 Aug 3 [cited 2019 Aug 5]. Available from: https://www.merriam-webster.com/dictionary/existential.

8. Puchalski CM. The role of spirituality in health care. Baylor University Medical Center Proceedings. 2001 Oct;14(4):352-7. [cited 2019 Jul 31]. Available from: https://www.ncbi.nlm.nih.gov/ pmc/articles/PMC1305900/.

9. Pasala ML. Spiritual well-being and death anxiety among older adults [Thesis]. Quezon City: Ateneo De Manila University; 2006. Approximately 20 p. Available from: Ateneo De Manila University, Quezon City, Philippines.

10. Janssen DJ, Boyne JJ, Jorg L, et al. Religious beliefs towards the end of life among elderly patients with chronic heart failure and the relationship with end-of-life preferences. Journal of Palliative Care and Medicine. 2016 Jan 21;6(1):1-8. [cited 2017 Nov 17]. Available from: https://www.omicsonline.org/open-access/religious-beliefstowards-the-end-of-life-among-elderly-patients-withchronic-heartfailure-and-the-relationship-with-endoflife-pre-2165-7386-1000244. php?aid=66888. DOI: $10.4172 / 2165-7386.1000244$.

11. Saad M, De Madeiros R. Spiritual-religious coping - health services empowering patients' resources [Online]. 2012 Oct 17 [cited 2019 Jul 31]. Available from: https://www.intechopen.com/books/ complementary-therapies-for-the-contemporary-healthcare/spiritualreligious-coping-health-services-empowering-patients-resources).

12. Abe-Kim J, Gong F, Takeuchi D. Religiosity, spirituality, and helpseeking among Filipino-Americans: Religious clergy or mental health professionals? Journal of Community Psychology. 2004 Sep 21;32(6):675-89. [cited 2018 Apr 20]. Available from: https:// onlinelibrary.wiley.com/doi/full/10.1002/jcop.20026. DOI: https:// doi.org/10.1002/jcop.20026.

13. Stanford School of Medicine, Health beliefs and behaviors [Online]. 2018 [cited 2018 Apr 20]. Available from: https://geriatrics.stanford. edu/ethnomed/filipino/fund/health_beliefs/health_behaviors.ht ml.

14. Lagman R, Woo G, Levine E, Donnell K, Lim H. Leaving it to God: Religion, spirituality and Filipina-American breast cancer survivors. Journal on Religion and Health. 2012 Oct 17;53(2):449-60. [cited 2018 Jan 31]. Available from: http://dx.doi.org/10.1007/s10943-0129648-z. DOI: https://doi.org/10.1007/s10943-012- 9648-z.

15. McCaffrey N, Bradley S, Ratcliffe J, Currow DC. What aspects of quality of life are important from palliative care patients' perspectives? A systematic review of qualitative research. Journal of Pain and Symptom Management. 2016 Aug;52(2):318-28.e5. [cited 2018 Jan 31]. Available from: https://doi.org/10.1016/j.jpainsymman.2016.02.012.

16. Science Daily, How spiritual beliefs relate to cancer patients' physical, mental, and social well-being [Online]. 2018 [cited 2018 Mar 9]. Available from: www.sciencedaily.com/releases/2015/08/ 150810071029.htm.

17. Kaliampos A, Roussi P. Religious beliefs, coping, and psychological well-being among Greek cancer patients. Journal of Health Psychology. 2015 Nov 26;22(6):754-64. [cited 2018 Mar 9]. Available from: http://journals.sagepub.com/doi/abs/10.1177/1359105315614995.

18. World Health Organization, Global atlas of palliative care [Online]. 2018 [cited 2018 Jan 31]. Available from: http://www.who.int/nmh/ Global_Atlas_of_Palliative_Care.pdf/.

19. Ngelangel CA, Wang EH. Cancer and the Philippine cancer control program. Japanese Journal of Clinical Oncology. 2002 Feb 1;32 Suppl:S52-61. [cited 2018 Jan 31]. Available from: https:// academic.oup.com/jjco/article/32/suppl_1/S52/881618. DOI: https:// doi.org/10.1093/jjco/hye126.

20. Laudico A, Medina V, Mirasol-Lumague M, et al. 2010 Philippine cancer facts and estimates [Online]. 2010 [cited 2017 Nov 17]. Available from: http://www.philcancerorgph.ipage.com/wp-content/ uploads/2014/04/2010-Philippine- Cancer-Facts-Estimates.pdf.

21. Richardson P. Spirituality, religion and palliative care. Annals of Palliative Medicine. 2014 Jul;3(3):150-9. [cited 2018 Jan 31]. Available from: http://dx.doi.org/10.3978/j.issn.2224-5820.2014.07.05.
22. Borneman T, Ferrell B, Puchalski C. Evaluation of the FICA tool for spiritual assessment. Journal of Pain and Symptom Management. 2010 Aug;40(2):163-73. [cited 2018 Jan 31]. Available from: http:// dx.doi.org/10.1016/j.jpainsymman.2009.12.019.

23. Fisher $\mathrm{J}, \mathrm{Ng} \mathrm{D}$. Presenting a 4-item spiritual well-being index (4-ISWBI). Religions. 2017 Sep 4;8(179):1-13. [cited 2018 Jan 31]. Available from: http://dx.doi.org/10.3390/rel8090179.

24. Functional Assessment of Chronic Illness Therapy (FACIT), FACITSp (Version 4) [Online]. 2018 [revised 2007 Nov 16; cited 2018 Feb 4]. Available from: www.facit.org/LiteratureRetrieve. aspx?ID $=42314$.

25. Sun V, Kim J, Irish T, et al. Palliative care and spiritual well-being in lung cancer patients and family caregivers. Psycho-Oncology. 2015 Sep 16;25(12):1448-55. [cited on 2018 Jan 31]. Available from: http://dx.doi.org/10.1002/pon.3987.

26. Thuné-Boyle IC, Stygall J, Keshtgar MR, Davidson TI, Newman SP. The impact of a breast cancer diagnosis on religious/spiritual beliefs and practices in the UK. Journal of Religion and Health. 2011 Jun;50(2):203-18. [cited 2018 Dec 5]. Available from: https://www.ncbi.nlm.nih.gov/pubmed/20094796 DOI: 10.1007/ s10943-010-9322-2.

27. Mitchell J, Lannin DR, Mathews HF, Swanson MS. Religious beliefs and breast cancer screening. Journal of Women's Health. 2002 Dec;11(10):907-15. [cited 2018 Dec 5]. Available from: https://www.ncbi.nlm.nih.gov/pubmed/12626089. DOI: https://doi. org/10.1089/154099902762203740.

28. Kim GJ, Goldstein L. The effects of religion and spirituality on coping efficacy for death and dying. Practical Pain Management. 2017 Nov 9;17(7):1-2. [cited 2018 Dec 5]. Available from: https:// www.practicalpainmanagement.com/resources/hospice/effectsreligion-spirituality-coping-efficacy-death-dying.

29. Banning M, Hafeez H, Hassan M, Faisal S, Zafar A. The impact of culture, sociological and psychological issues on Muslim breast cancer patients in Pakistan. Cancer Nursing. 2009 JulAug;32(4):317-24. [cited 2018 Dec 5]. Available from: https://bura. brunel.ac.uk/bitstream/2438/8147/2/Fulltext.pdf. DOI: 10.1097/ NCC.0b013e31819b240f.

30. Breastcancer.org, Spirituality and prayer [Online]. 2019 [cited 2018 Dec 5]. Available from: https://www.breastcancer.org/treatment/ comp_med/types/spirituality.

31. Seitsamo J, Tuomi K, Martikainen R. Activity, functional capacity, and well-being in ageing Finnish workers. Occupational Medicine. 2007 Mar;57(2):85-91. [cited 2018 Dec 5]. Available from: https:// www.researchgate.net/publication/6752683_Activity_functional_ capacity_and_well-being_in_ageing_Finnish_workers.

32. Purnell LD. Chapter 13: People of Filipino heritage. In: Purnell LD. Transcultural health care: A culturally competent approach, 4th ed. Philadelphia: F.A. Davis Company; 2013 [cited 2018 Dec 5]. pp. 228-49. Available from: https://books.google.com.ph.

33. Rettger J, Wall K, Corwin D, Davidson A, Lukoff D, Koopman C. In psycho-spiritual integrative therapy for women with primary breast cancer, what factors account for the benefits? Insights from a multiple case analysis. Healthcare. 2015 May 12;3(2):263-83. [cited 2018 Dec 5]. Available from: https://www.ncbi.nlm.nih.gov/pmc/ articles/PMC4939536/. DOI: 10.3390/healthcare3020263.

34. Lin $\mathrm{H}$, Bauer-Wu SM. Psycho-spiritual well-being in patients with advanced cancer: An integrative review of the literature. Journal of Advanced Nursing. 2003 Sep 3;44(1):69-80. [cited 2018 Jan 31]. Available from: http://dx.doi.org/10.1046/j.1365-2648. 2003.02768.x.

35. Eckersley R. Culture, spirituality, religion and health: Looking at the big picture. The Medical Journal of Australia. 2007 May 21;186(10 Suppl):S54-6. [cited 2018 Dec 5]. Available from: https://www.mja.com.au/journal/2007/186/10/culture-spiritualityreligion-and-health-looking-big-picture. DOI: 10.5694/j.1326-5377. 2007.tb01042.x. 